\title{
TOTAL CALCIUM AND ALBUMIN CORRECTED CALCIUM AS PROGNOSTIC SEVERITY MARKERS IN ACUTE PANCREATITIS
}

\author{
General Surgery \\ Dr. Madhu B S \\ Professor, Department Of General Surgery, Mysore Medical College \& Research \\ Institute, Mysore, Karnataka. \\ Dr. Vikas $V^{*}$ \\ Post Graduate Student, Department Of General Surgery, Mysore Medical College \& \\ Research Institute, Mysore, Karnataka. *Corresponding Author
}

\section{ABSTRACT}

AIM: to assess the Total Calcium and Albumin-Corrected Calcium as prognostic severity markers and Organ dysfunction. BACKGROUND: Acute pancreatitis having variable involvement of regional tissues or remote organ systems can lead to high mortality rate in severe form. Early assessment to identify severity becomes essential. MATERIALS \& METHODOLOGY: A prospective study was conducted in K.R.Hospital, Mysore Medical College \& Research Institute, from November 2019 to July 2020. All cases of Acute Pancreatitis during this period were assessed for severity and Total Calcium and Albumin Corrected calcium were assessed in them to assess the severity and their correlation. RESULTS: A total of 96 patients were included in the study and in accordance with the updated Atlanta Classification, 63 patients presented with mild AP, 22 with moderately severe AP, and 11 with severe AP. The maximum TC cut-off point was $7.5 \mathrm{mg} / \mathrm{dL}$, with values of S, 90.9\%; Sp, 78.8\%; PPV, 35.7\%, and NPV, 98.5\%. The maximum ACC cut-off point was $7.25 \mathrm{mg} / \mathrm{dL}$, with values of S, 81.8\%; Sp, 80\%; PPV, 34.6\%; NPV, $97.1 \%$ respectively CONCLUSIONS: TC and ACC, measured within the first 24 hours, are useful severity predictors in acute pancreatitis, with sensitivity and predictive values comparable or superior to those of the conventional prognostic scales.

\section{KEYWORDS}

Severe Acute Pancreatitis, Total Serum Calcium, Albumin Corrected Calcium

\section{INTRODUCTION}

Acute pancreatitis (AP) has been defined as an "acute inflammatory process of the pancreas with variable involvement of other regional tissues or remote organ systems" ${ }^{\text {"[1] }}$. It has a multiple modes of presentation with many laboratory parameters to diagnose, with multiple modalities of treatment varying from conservative management to surgery, with both high rates of morbidity and mortality. Patients with mild AP have mortality rates of less than $1 \%$, but over $25 \%$ of cases involving AP are severe, with mortality as high as $10 \%{ }^{[2,3]}$

Early assessment of severity is vital in management of cases of severe acute pancreatitis. It helps us to identify patients at high risk of morbidity and mortality and to transfer them to an intensive care unit for closer supervision and required early interventions. The Atlanta Symposium in 1992 attempted to offer a global 'consensus' and a clinically based universally applicable classification system for severity and complications of $\mathrm{AP}^{[1]}$

The Atlanta classification was revised in 2012, which includes a clinical assessment of severity of acute pancreatitis and provides more objective terms to describe the local complications of acute pancreatitis and categorizes AP into 3 states based on the presence of organ failure or local complications: mild, moderate, and severe ${ }^{[4]}$. Modified Marshall scoring system determines the organ failure ${ }^{[5]}$.

The search for a tool that can improve on the clinical assessment has been ongoing for decades. Ideally, such a tool should be simple, inexpensive, noninvasive, easily applicable, and reproducible and have the statistical power to arrive to a valid conclusion accurately. Many scoring systems are advocated for determining the severity, but need a comprehensive assessment and multiple investigations for completing the scoring systems.

Biochemical markers have also turned out to be useful predictors. Examples of some of them are: C-reactive protein, procalcitonin, interleukin-6, thioredoxin-1, and polymorphonuclear elastase. ${ }^{[6]}$. Hypocalcemia has been associated with AP severity but its etiopathogenesis has been a subject of debate for decades.

Animal experimental models used in many studies on Acute Pancreatitits have shown that 6 to $8 \mathrm{~h}$ after pancreatitis induction, ionized calcium and total calcium concentrations decrease, along with the fact that the accumulation of calcium in the soft tissues is associated with onset of hypocalcemia. ${ }^{[7}$

Total Calcium has been used in some of the AP prognostic severity scales and also evaluated as a mortality prognostic factor and a predictor of severe AP with infection. ${ }^{[8]}$ Although Albumin-corrected calcium (ACC) has been associated with severity of acute pancreatitis, AAC within the first $24 \mathrm{~h}$ of the patient's hospital admission has not been extensively studied as an independent prognostic severity factor.

Total calcium and Albumin-corrected calcium can be readily measured, calculated, interpreted by any health personnel and can be used as simplified markers to predict severity.

This study tries to assess the Total Calcium and Albumin-Corrected Calcium as prognostic severity markers and Organ dysfunction.

\section{MATERIALS \& METHODOGY}

This was a prospective study conducted in K.R.Hospital, Mysore Medical College \& Research Institute, a tertiary care centre from November 2019 to July 2020. Inclusion criteria included all patients above 18 years of age, who presented within 72 hours of onset of epigastric pain

The diagnosis of Acute Pancreatitis was made based on the American College of Gastroenterology recommendations, and the presence of 2 of the 3 following characteristics was established: intense epigastric pain, serum amylase or lipase $\geq 3$ times above the normal limit, and characteristic AP findings in the CT images. ${ }^{[9]}$

The following clinical and demographic data with respect to gender, age, previous history of pancreatitis, total calcium taken within $24 \mathrm{~h}$ of admission, serum albumin, amylase and lipase and imaging data in the cases of patients with severe or moderately severe acute pancreatitis were collected.

Routine biochemical and hematological parameters were measured using an autoanalyzer machine available in the hospital laboratory. Using Biotech 3000 Analyzer using Cresolphthalein method, Serum calcium was calculated, and using bromocresol green method, serum albumin was calculated.

The modified Marshall score as a predictor of Organ dysfunction was determined at admission and at 48 hours and at any point of time during admission as per the need of the patient.$^{[4]}$ Diagnosis of acute pancreatitis, its severity, and local and systemic complications were defined as per the Revised Atlanta Classification 2012.

Using Revised Atlanta Classification, patients were assessed and divided into three groups based on severity of acute pancreatitis as : Severe Acute Pancreatitis (associated with persistent organ failure longer than $48 \mathrm{hrs}$ with or without local or systemic complications); Moderately Severe Acute Pancreatitis (that presents with local or systemic complications, with no persistent organ failure); and Mild Acute Pancreatitis (with no organ failure or local or systemic 
complications) ${ }^{[4]}$

In order to evaluate $\mathrm{TC}$ and $\mathrm{ACC}$ as prognostic factors of severity, the lowest TC values were collected within the first $24 \mathrm{~h}$ of hospital admittance. These values were then corrected according to the serum albumin level (see formula), thus obtaining the ACC. ${ }^{[10]}$

$\mathrm{ACC}=\mathrm{TC}+(0.8 *[4-$ Serum Albumin concentration $])$

\section{DATAANALYSIS}

Data analysis was based on descriptive statistics to determine the general population characteristics. The one-way ANOVA test, i.e the Kruskal-Wallis test and the chi square test were employed to establish the statistical significance of the differences between groups, based on the characteristics of the analyzed variables. Statistical significance was determined with $p<0.05$. ROC curves were used in order to establish the possible cutoff values for TC and ACC.

The maximum cut-off value was utilized to calculate the sensitivity (S), specificity (Sp), positive predictive value (PPV), negative predictive value (NPV), positive likelihood ratio(PLR), and negative likelihood ratio (NLR) of each criterion by means of contingency tables. Odds ratio (OR) was employed to evaluate the cut-off values as relative risks for developing severe pancreatitis. All the statistical analyses were done using Statistical Package for the Social Sciences Programme v.26(IBM SPSS 26)

Out of 96 patients, 43 patients $(44.79 \%)$ had biliary pancreatitis, 40 patients $(41.16 \%)$ had alcohol induced pancreatitis, while 13 patients $(13.54 \%)$ had other etiological factors for pancreatitis. There was no significant association between etiology and severity of the disease $(\mathrm{P}$ $>0.05)$.

Table 1. Etiology of pancreatitis

\begin{tabular}{|c|c|}
\hline Etiology & No. of patients (\%) \\
\hline Biliary Pancreatitis & $43(44.79)$ \\
\hline Total number of Tyre Factories & $40(41.16)$ \\
\hline Idiopathic & $12(12.5)$ \\
\hline Drug induced & $1(1.04)$ \\
\hline
\end{tabular}

The one-way ANOVA test with the Tukey-B post hoc test showed significant differences in the TC concentration of the patients in the 3 groups with mean total calcium $8.23,7.3$ and 6.62 for mild, moderate, and severe AP, respectively $(\mathrm{p}=0.002)$; also the mean ACC in patients with severe and moderate AP were significantly lower when compared to those with mild AP with 7.94, 7.04, and 6.35 for mild, moderate, and severe AP, respectively $(\mathrm{p}=0.001)$ as seen in Table 3 .

A receiver-operating characteristic (ROC) analysis of the total calcium was analyzed for severe acute pancreatitis, AUC of which came out to be 0.881 , which was significant ( $p$ value: 0.001 ). Similarly, ROC curve of albumin-corrected calcium analyzed for severe acute pancreatitis showed AUC of 0.883 , which was also significant ( $p$ value: 0.001 ). The ROC curves of TC and ACC were comparable as shown in Table 2 and Figure 1 .

\section{Table 2. Area under the curve}

\begin{tabular}{|c|c|c|c|c|c|}
\hline \multirow[t]{2}{*}{ Test Result Variable(s) } & \multirow[t]{2}{*}{ Area } & \multirow{2}{*}{\begin{tabular}{|c|} 
Std. \\
Error
\end{tabular}} & \multirow{2}{*}{\begin{tabular}{c|}
$p$ \\
value
\end{tabular}} & \multicolumn{2}{|c|}{$95 \% \mathrm{CI}$} \\
\hline & & & & $\begin{array}{l}\text { Lower } \\
\text { Bound }\end{array}$ & $\begin{array}{l}\text { Upper } \\
\text { Bound }\end{array}$ \\
\hline Total Calcium & 0.881 & 0.073 & 0.001 & 0.738 & 1.000 \\
\hline Albumin Corrected Calcium & 0.883 & 0.071 & 0.001 & 0.744 & 1.000 \\
\hline
\end{tabular}
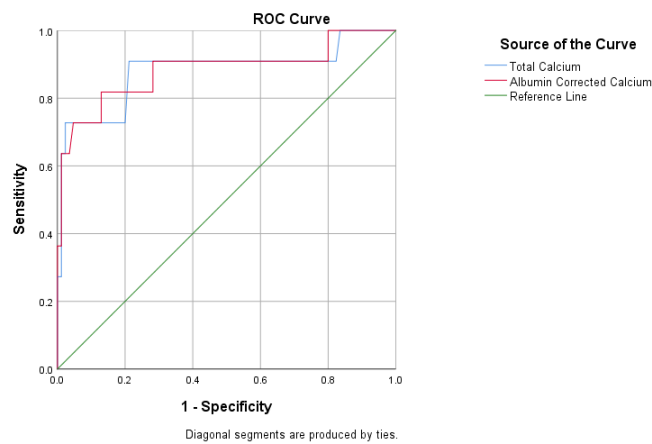

Figure 1: ROC Curve for Total Calcium \& Albumin Corrected Calcium.
Table 3. Population Distribution and Correlation between TC, ACC and Severity of Pancreatitis

\begin{tabular}{|c|c|c|c|c|c|}
\hline Factor & $\begin{array}{c}\text { Total } \\
\text { Population } \\
\mathbf{n = 9 6}\end{array}$ & $\begin{array}{c}\text { Mild Acute } \\
\text { Pancreatitis } \\
\mathbf{n = 6 3}\end{array}$ & $\begin{array}{c}\text { Moderately } \\
\text { Severe } \\
\text { Acute } \\
\text { Pancreatitis } \\
\mathbf{n = 2 2}\end{array}$ & $\begin{array}{c}\text { Severe } \\
\text { Acute } \\
\text { Pancreatitis } \\
\mathbf{n = 1 1}\end{array}$ & $\begin{array}{c}\mathbf{p} \\
\text { value }\end{array}$ \\
\hline $\begin{array}{c}\text { Total Serum } \\
\text { Calcium } \\
\text { (mg/dl), } \\
\text { Mean } \pm \text { SD }\end{array}$ & $7.83 \pm 0.76$ & $8.23 \pm 0.459$ & $7.30 \pm 0.421$ & $6.662 \pm$ & 0.002 \\
\hline Albumin & $7.53 \pm$ & $7.94 \pm 0.432$ & $7.046 \pm$ & $6.350 \pm$ & 0.001 \\
Corrected & 0.751 & & 0.455 & 0.907 & \\
Calcium \\
(mg/dl),
\end{tabular}

Table 4. Diagnostic values of TC, $\mathrm{ACC}$ in relation to Severe Acute Pancreatitis

\begin{tabular}{|l|l|l|l|l|l|}
\hline Factor & Sensitivity & Specificity & PPV & NPV & p value \\
\hline $\begin{array}{l}\text { Total serum calcium } \\
(<7.50 \mathrm{mg} / \mathrm{dl})\end{array}$ & $90.9 \%$ & $78.8 \%$ & $35.7 \%$ & $98.5 \%$ & 0.002 \\
\hline $\begin{array}{l}\text { Total Serum Calcium } \\
(<6.75 \mathrm{mg} / \mathrm{dl})\end{array}$ & $72.7 \%$ & $96.5 \%$ & $72.7 \%$ & $96.5 \%$ & 0.001 \\
\hline $\begin{array}{l}\text { Albumin Corrected } \\
\text { Calcium } \\
(<7.25 \mathrm{mg} / \mathrm{dl})\end{array}$ & $81.8 \%$ & $80 \%$ & $34.6 \%$ & $97.1 \%$ & 0.001 \\
\hline $\begin{array}{l}\text { Albumin Corrected } \\
\text { Calcium } \\
(<6.50 \mathrm{mg} / \mathrm{dl})\end{array}$ & $70.6 \%$ & $96.5 \%$ & $70 \%$ & $95.3 \%$ & 0.001 \\
\hline
\end{tabular}

When the coordinates on the curve were analyzed, TC of $7.50 \mathrm{mg} / \mathrm{dl}$ was computed as cutoff for severe AP with sensitivity of $90.9 \%$, specificity of $78.8 \%$, PPV of $35.7 \%$ and NPV of $98.5 \%$. Also, when the coordinates on the curve for ACC were analyzed, ACC of $7.25 \mathrm{mg} / \mathrm{d}$ was computed as cutoff for severe AP with sensitivity of $81.8 \%$, specificity of $80 \%$, PPV of $34.6 \%$, and NPV of $97.1 \%$. (Table 4 )

\section{DISCUSSION}

Acute pancreatitis remains a common disease with mortality of severe attacks reaching as high as $30 \%$ to $50 \%{ }^{[11]}$. These patients need emergent diagnosis and prompt grading of severity for them to be treated aggressively to prevent morbidity and mortality. Also early detection of mild disease prevents unnecessary over treatment, thus reducing the economic burden.

In 1974 by Ranson et al. for acute alcohol-induced pancreatitis, severity assessment in acute pancreatitis was first started and remains the most commonly used system ${ }^{[12]}$. The Ranson, Glasgow, and APACHE II score are few of the commonly used scoring systems ${ }^{[12,13]}$ To complete Ranson and Glasgow scoring systems, it takes 48 hours to complete the assessment, hence the delay in scoring; APACHE II score is very cumbersome to calculate ${ }^{[13]}$.

Hypocalcemia is one of the components of Ranson's scoring system done to assess the severity of pancreatitis, but usually assessed at $48 \mathrm{hrs}$. Ammori et al reported that during severe attack, hypocalcaemia was observed more frequently as compared to mild attack of pancreatitis $(86 \% \text { versus } 39 \%)^{[14]}$. Depending on the setting and cutoffs used, in critically ill patients, prevalence of hypocalcaemia ranges between $15 \%$ and $88 \%{ }^{[15]}$.

Proposed mechanisms for hypocalcaemia in early phase are release of free fatty acids, which form calcium salts, autodigestion of mesenteric fat by pancreatic enzymes and transient hypoparathyroidism, and hypomagnesemia. ${ }^{[16,17,18]}$

Sepsis is most common complication in the later stages of pancreatitis Whitted et al proposed that in sepsis, increased circulating catecholamines cause a shift of circulating calcium into the intracellular compartment, leading to relative hypocalcemia. By negative feedback loop, this causes increased PTH secretion, leading to further increase in intracellular calcium overload, oxidative stress, and cell death. ${ }^{[19]}$. Hypomagnesaemia-induced impaired PTH secretion and action, vitamin D deficiency and relative PTH deficiency are some of the other plausible causes.

The largest multicenter study conducted in four hospitals of Australia on a cohort of 7024 patients showed that $\mathrm{Ca}<0.8 \mathrm{mmol} / \mathrm{L}$ was an 
independent predictor of mortality in intensive care unit (ICU) patients. ${ }^{[20]}$

Steele et al. in a retrospective single-centre observational study on 1038 critically ill patients found that $55.2 \%$ patients had hypocalcemia $(\mathrm{Ca}<1.1 \mathrm{mmol} / \mathrm{L})$ at admission. Serum calcium normalized by day 4 in most patients. Calcium level normalization was not different in patients who received and who did not receive calcium supplementation. Patients with severe hypocalcemia $(0.9 \mathrm{mmol} / \mathrm{L})$ who failed to normalize their calcium level by day 4 had increased mortality $(38 \%$ vs. $19 \%$ ); however, the values did not reach statistical significance. Authors suggested that hypocalcemia patients who fail to correct their level spontaneously might form the subgroup of patients likely to benefit from intervention. ${ }^{[2]}$

In our study, severity of AP was not related to the age of the patient. There was no difference between age, sex, gender and the severity of AP in our study. Similarly, there was no association between etiology and severity of AP.

As TC and ACC to be considered as a biochemical marker for severe acute pancreatitis, our study was able to demonstrate a specificity and sensitivity values for Total Serum Calcium with a cut-off point of 7.5 $\mathrm{mg} / \mathrm{dl}$ has a sensitivity of $90.9 \%$, specificity of $78.8 \%$, PPV of $35.7 \%$, and NPV of $98.5 \%$. For total calcium with a cut off of $6.5 \mathrm{mg} / \mathrm{dl}$ the sensitivity decreased to $72.7 \%$ however specificity was about $96.5 \%$.

With regard to albumin corrected calcium, with the $7.25 \mathrm{mg} / \mathrm{dl}$ cut-off point, its sensitivity was $81.8 \%$ and specificity was $80 \%$. With the 6.5 $\mathrm{mg} / \mathrm{dl}$ cut-off point, its sensitivity was $70.6 \%$ and specificity was 96.5 $\%$.

These high prediction levels and the ease in calculating them when the serum albumin level is known, make obtaining the albumin corrected calcium concentration worthwhile, since it considerably increases diagnostic accuracy.

When we compare the sensitivity, specificity, and predictive values of TC and ACC, TC seems to better predict the severity of acute pancreatitis as the value of ACC varied with various other parameters including the nutritional status and chronic liver disease, and it also takes a little time for albumin to get depleted in diseases.

A large number of health care centers have access to TC and ACC use, but not as many have access to the resources required for using the APACHE-II scale and other AP severity markers, such as C-reactive protein, interleukin 6 , or procalcitonin. Serum calcium and albumin for calculating ACC are simple biochemical markers that are routinely determined in the majority of hospital centers. Their use as prognostic factors of severity in AP would be valuable for identifying those persons who require intensive care, even at the primary and secondary care center levels.

\section{CONCLUSION}

Serum calcium and albumin-corrected calcium obtained within the first 24 hours of hospital admission are useful predictors of severity in acute pancreatitis. This will not replace the current accepted scoring systems for severity. As these can be readily measured, with an adequate interpretation of their cutoff points, they can be used routinely in every case of acute pancreatitis to assess its severity, predict complications, and identify the patients who require intensive care support even in primary and secondary care centres.

\section{REFERENCES}

1. Bradley EL, 3rd. A clinically based classification system for acute pancreatitis Summary of the International Symposium on Acute Pancreatitis, Atlanta, Ga, September 11 through 13, 1992. Arch Surg 1993;128(5):586-590

2. Steinberg W, Tenner S. Acute pancreatitis. N Engl J Med 1994;330(17):1198-1210.

3. Dominguez-Munoz JE, Carballo F, Garcia MJ, de Diego JM, Campos R, Yanguela J, de la Morena J. Evaluation of the clinical usefulness of APACHE II and SAPS systems in the initial prognostic classification of acute pancreatitis: a multicenter study. the initial prognostic classification of acute pancreatitis: a multicenter study. Pancreas 1993;8(6):682-686.

4. P. A. Banks, T. L. Bollen, C. Dervenis et al., "Classification of acute pancreatitis-2012: revision of the Atlanta classification and definitions by international consensus," Gut, vol. 62 , no. 1 ,pp. 102-111, 2013

5. M. G. Sarr, "2012 Revision of the Atlanta Classification of acute pancreatitis," Polskie Archiwum Medycyny Wewnetrznej, vol. 123, no.3, pp. 118-124, 2013.

6. Gurda-Duda A, Ku'snierz-Cabala B, Nowak W, et al. Assessment of the prognostic value of certain acute-phase proteins and procalcitonin in the prognosis of acute pancreatitis. Pancreas. 2008;37:449-53.

7. Bhattacharya SK, Luther RW, Pate JW, et al. Soft tissue calcium and magnesium content in acute pancreatitis in the dog: calcium accumulation, a mechanism for hypocalcemia in acute pancreatitis. J Lab Clin Med. 1985;105:422-7
8. Lee BJ, Kim CD, Jung SW, et al. [Analysis of the factors that affect the mortality rate in severe acute pancreatitis]. Korean J Gastroenterol. 2008;51:25---33

Banks PA, Freeman ML, The Practice Parameters Committee of the American College of Gastroenterology. Practice Guidelines in Acute Pancreatitis. Am J Gastroenterol. 2006;101:2379-400

10. Dickerson RN, Alexander KH, Minard G, et al. Accuracy of methods to estimate ionized and "corrected" serum calcium concentrations in critically ill multiple trauma patients receiving specialized nutrition support. J Parenter Enteral Nutr.2004;28:133-4

11. Bhatia M, Wong FL, Cao Y, Lau HY, Huang J, Puneet P, Chevali L. Pathophysiology of acute pancreatitis. Pancreatol.2005;5(2-3):132-44.

12. J. H. C. Ranson, K. M. Rifkind, D. F. Roses, S. D. Fink, K. Eng, and F. C. Spencer, "Prognostic signs and the role of operative management in acute pancreatitis," Surgery, Gynecologyand Obstetrics, vol. 139, no. 1, pp. 69-81,1974.

13. W. R. Matull, S. P. Pereira, and J. W. O'Donohue, "Biochemical markers of acute pancreatitis," Journal of Clinical Pathology, vol. 59, no. 4, pp. 340-344, 2006

14. Ammori BJ, Barclay GR, Larvin M, McMahon MJ. Hypocalcemia in patients with acute pancreatitis: a putative role for systemic endotoxin exposure. Pancreas. 2003:26(3):213 7.

15. Zivin JR, Gooley T, Zager RA, Ryan MJ. Hypocalcemia: a pervasive metabolic abnormality in the critically ill. Am J Kidney Diseases. 2001:37(4):689-98.

16. Condon JR, Ives D, Knight MJ, Day J. The aetiology of hypocalcaemia in acute pancreatitis. Br J Surg. 1975:62(2):115-8

17. McMahon MJ, Woodhead JS, Hayward RD. The nature of hypocalcaemia in acute pancreatitis. Br J Surg. 1978:65(3):216-8

18. Ryzen E, Rude RK. Low intracellular magnesium in patients with acute pancreatitis and hypocalcemia. Western J Med.1990:152(20):145-8.

19. Whitted AD, Stanifer JW, Dube P. A dyshomeostasis of electrolytes and trace elements in acute stressor states: impact on the heart. Am J Med Sci. 2010:340(1):48-53

20. Egi M, Kim I, Nichol A. Ionized calcium concentration and outcome in critical illness Critical Care Med. 2011:39(2):314-21

21. Steele T, Kolamunnage-Dona R, Downey C, Toh CH, Welters I. Assessment and clinical course of hypocalcemia in critical illness. Critical Care. 2013;17(3):R106. 